\title{
White Coat Hypertension is a Pioneer Sign of Metabolic Syndrome
}

\author{
Mehmet Rami Helvaci ${ }^{1^{*}}$ and Ali Ozcan ${ }^{2}$ \\ ${ }^{1}$ Professor of Internal Medicine, Medical Faculty of the Mustafa Kemal University, Hatay, Turkey \\ ${ }^{2}$ Professor of Biochemistry, Medical Faculty of the Mustafa Kemal University, Hatay, Turkey
}

"Corresponding author: Mehmet Rami Helvaci, Professor of Internal Medicine, Medical Faculty of the Mustafa Kemal University, 31100, Serinyol, Antakya, Hatay, Turkey, Tel: 90-326-2291000 (Internal 3399); Fax: 90-326-2455654; E-mail: mramihelvaci@hotmail.com

Received date: March 11, 2014; Accepted date: January 05, 2015; Published date: January 10, 2015

Copyright: ( 2015 Helvaci RM, et al. This is an open-access article distributed under the terms of the Creative Commons Attribution License, which permits unrestricted use, distribution, and reproduction in any medium, provided the original author and source are credited.

\begin{abstract}
Metabolic syndrome is an accelerated systemic atherosclerotic process terminating with obesity, hypertension, diabetes mellitus, peripheric artery disease, chronic renal disease, chronic obstructive pulmonary disease, cirrhosis, coronary heart disease, stroke, and eventually early aging and death. It shows itself with some reversible components including smoking, overweight, hyperbetalipoproteinemia, hypertriglyceridemia, dyslipidemia, impaired fasting glucose, impaired glucose tolerance, and white coat hypertension (WCH). The terminal consequences are probably due to the smoking and excess weight induced chronic inflammatory process on the endothelial system for a long period of time. $\mathrm{WCH}$ is a pioneer sign of the accelerated systemic atherosclerotic process that can be detected easily, and treated by preventing weight gain.
\end{abstract}

Keywords: White coat hypertension; Metabolic syndrome; Atherosclerosis

\section{Introduction}

A causative relationship between excess weight and systemic atherosclerosis is known for many years under the title of metabolic syndrome $[1,2]$. The syndrome is characterized by a low-grade chronic inflammatory process probably initiated in early life, and can be slowed down with appropriate nonpharmaceutical approaches including lifestyle changes, diet, and exercise [3,4]. But probably the syndrome cannot be prevented completely, since aging alone may be one of the significant facilitator factor of the systemic atherosclerotic process. The metabolic syndrome may contain early reversible indicators such as white coat hypertension $(\mathrm{WCH})$, impaired fasting glucose (IFG), impaired glucose tolerance (IGT), hypertriglyceridemia, hyperbetalipoproteinemia, dyslipidemia, overweight, and smoking for the development of irreversible diseases including obesity, hypertension (HT), type 2 diabetes mellitus (DM), peripheric artery disease (PAD), coronary heart disease (CHD), chronic obstructive pulmonary disease (COPD), cirrhosis, chronic renal disease (CRD), stroke, and eventually early aging and death [5]. In another word, the syndrome induced systemic atherosclerosis is probably the leading cause of death for both sexes all over the world. For example, prevalences of hypertriglyceridemia, hyperbetalipoproteinemia, dyslipidemia, IGT, and WCH had a parallel fashion to excess weight by increasing until the seventh decade of life and decreasing afterwards ( $p<0.05$ nearly in all steps) in a previous study [6]. On the other hand, prevalences of HT, DM, and CHD always continued to increase without any decrease by decades ( $\mathrm{p}<0.05$ nearly in all steps) indicating their irreversible natures [6]. After development of one of the terminal consequences, the nonpharmaceutical approaches will provide little benefit to prevent development of the others probably due to cumulative effects of the risk factors on the endothelial system for a long period of time $[7,8]$. According to our opinion, obesity should be included among the terminal consequences of the syndrome since after development of obesity; pharmaceutical and nonpharmaceutical approaches will provide little benefit either to heal obesity or to prevent its complications.

Excess weight probably initiates to a chronic and low-grade inflammatory process on many systems, especially on the endothelial system, and risk of death from all causes including cardiovascular diseases and cancers increases parallel to the range of moderate to severe weight excess in all age groups [9]. The effects of weight on blood pressure (BP) were also shown previously that the prevalence of normotension (NT) was significantly higher in the underweight $(80.3 \%)$ than the normal weight $(64.0 \%)$ and overweight cases $31.5 \%$, $\mathrm{p}<0.05$ for both) and $55.1 \%$ of cases with HT had obesity against $26.6 \%$ of cases with NT $(\mathrm{p}<0.001)$ in another study $[10,11]$. So the dominant underlying causative factor of the metabolic syndrome appears as an already existing excess weight or a trend towards excess weight, which is probably the main cause of insulin resistance, dyslipidemia, IFG, IGT, and WCH [4]. Even prevention of the accelerating trend of weight with diet or exercise, even in the absence of a prominent weight loss, will probably result with resolution of many reversible indicators of the syndrome [12-14]. But according to our opinion, limitation of excess weight as an excess fat tissue in and around abdomen under the heading of abdominal obesity is meaningless, instead it should be defined as overweight or obesity via body mass index (BMI), since adipocytes function as an endocrine organ that produces a variety of cytokines and hormones in anywhere of the body [4]. The resulting hyperactivity of sympathetic nervous system and renin-angiotensinaldosterone system is probably associated with insulin resistance, elevated BP, and chronic endothelial inflammation. Similarly, the Adult Treatment Panel III reported that although some people classified as overweight with a large muscular mass, most of them also have excess fat tissue, and excess weight does not only predispose to $\mathrm{CHD}$, stroke, and several other atherosclerotic consequences, it also has a high burden of other CHD risk factors including dyslipidemia, DM, and HT [15].

Elevated BP increases risks of major cardiovascular events including renal failure, myocardial infarction, stroke, and cardiovascular death. 
But diagnosis and management of HT is complicated by the fact that BP varies greatly, depending on physical and mental stresses. Furthermore, the elderly people tend to have an abnormal circadian rhythm and a normally higher systolic BP than younger individuals. In addition, in the doctor's office in particular, measurements are often too high which is called as WCH. WCH is defined as office BP of $\geq$ $140 / 90 \mathrm{mmHg}$ for systolic and/or diastolic but home BP of $<135 / 85$ $\mathrm{mmHg}$ for both. According to our experience, there are many people using antihypertensive medication, which has been initiated just after a single office measurement, but actually being normotensive. A practicable and inexpensive supplementary method to avoid inaccurate results is home blood pressure measurement (HBPM). This approach may enable numerous measurements to be obtained, which can more accurately reflect the real situation than one offmeasurement in the physician's office. Since HBPM is easily accepted by patients, it is reasonable to recommend taking several measurements. For example, HBPM (mean of three to 38 measurements) was a better predictor of total mortality than office measurements at screening in the Ohasama study [16]. The authors have used a schedule for HBPM with a single morning measurement, and advised taking as many measurements as possible (preferably more than 14) for the best prediction of stroke risk. Additionally, recent $\mathrm{HT}$ guidelines propose $\mathrm{HBPM}$ as an important means to evaluate the response to antihypertensive treatment, to improve compliance with therapy, and most importantly, as an alternative to 24 hour ambulatory blood pressure measurement (ABPM) to confirm or refute the WCH [17]. HBPM is useful not only for diagnosis of HT but also for its management including choice and titration of antihypertensive drugs. A minimal antihypertensive effect and duration of action of antihypertensives can be determined by HBPM. The duration of action of drugs is established by the comparison of the antihypertensive effect in the morning with that in the evening. Appropriateness of HBPM to guide antihypertensive treatment was only tested in one large-scale randomized trial: the THOP (Treatment of Hypertension Based on Home or Office Blood Pressure) trial, in which it was shown that antihypertensive treatments based on home instead of office BP measurements led to a less intensive drug treatment, but also to less BP control with no difference in general well-being and left ventricular mass [18]. In another study, both HBPM and ABPM appeared to be appropriate methods for detection of masked hypertension (MHT) [19]. Similarly, we could not detect any significant difference for diagnosis of $\mathrm{WCH}$ and MHT between HBPM and ABPM and it was observed on ABPM that the white coat effect was initiated by leaving home to come to hospital [20]. Additionally, HBPM can provide a greater number of readings and, when automatic devices are used, an absence of observer bias. It may also reduce the number of doctor visits. Patients can use this method several times by themselves in a year without requiring any ambulatory device. It is also a less expensive method of BP monitoring. Furthermore, self-measurement can also reveal therapeutic effects more reliably and has a greater predictive value for organic damage. So HBPM should be the preferred method for the diagnosis of MHT and HT against office measurements and ABPM due to its simplicity and effectiveness, and should be applied to all people above the age of 40 years once a year due to high prevalence of $\mathrm{HT}$ and MHT in this age group.

There are various reports about the prognostic significance of $\mathrm{WCH}$ in the literature. In a 7.4 year follow-up study, there was no evidence that WCH exhibited a clearly higher risk for the development cardiovascular events [21]. In another study, complication risks of
WCH were not found as different from NT [22]. On the other hand, the intima-media thickness and cross-sectional area of the carotid artery were found to be similar in patients with WCH and HT, and significantly higher than patients with $\mathrm{NT}$, and the authors concluded that there is target organ damage in $\mathrm{WCH}$, and $\mathrm{WCH}$ should not be considered as an innocent trait [23]. It was reported in the Ohasama study that $\mathrm{WCH}$ is a risk factor for the development of home HT [16]. In an 8 -year follow-up study again, $46.9 \%$ of cases with WCH and $22.2 \%$ of cases with NT progressed to HT [24]. Similarly, plasma homocysteine levels were higher, and left ventricle mass index was greater in WCH compared to NT groups ( $<<0.001$ for both) [23]. It was reported in the literature that $\mathrm{WCH}$ is associated with some features of the metabolic syndrome and more than $85 \%$ of cases with the syndrome have elevated BP levels in another study $[4,25]$. On the other hand, we observed very high prevalences of WCH even in early decades, $23.2 \%$ in the third and $24.2 \%$ in the fourth decades of life [6]. The very high prevalences of $\mathrm{WCH}$ in society were also shown by some other studies $[26,27]$. When we compared the $\mathrm{NT}, \mathrm{WCH}$, and HT groups in another study prevalence of all health problems including obesity, IGT, DM, and CHD had significant progressions from the NT towards the $\mathrm{WCH}$ and $\mathrm{HT}$ groups, and the $\mathrm{WCH}$ group was found as a progression step in between [28]. But as an interesting result, the prevalence of dyslipidemia was the highest in the $\mathrm{WCH}$ group, and it was $41.6 \%$ among them versus $19.6 \%$ of NT $(\mathrm{p}<0.001)$ and $35.5 \%$ of HT groups' $(\mathrm{p}<0.05)$ [28]. Similar results indicating the higher prevalence of dyslipidemia in WCH cases were also observed in another study against to another study indicating serum trigliseride and cholesterol levels did not differ significantly between NT, WCH, and HT cases in men in the literature $[29,30]$. The relatively lower prevalence of dyslipidemia in HT group may be explained by the already increased adipose tissue per taken fat in HT cases, since prevalence of obesity was significantly higher in $\mathrm{HT}$ against $\mathrm{WCH}$ groups $(\mathrm{p}<0.01)$ [28]. So the detected higher prevalence of $\mathrm{WCH}$ even in early decades, despite the lower prevalence of excess weight in these age groups, may show a trend of getting weight and its terminal consequences. Probably all of the associations are closely related with the metabolic syndrome since WCH and dyslipidemia may be two initial signs of the syndrome. On the other hand, we accept WCH as a different entity from borderline/mild HT due to the completely normal HBPM and ABPM values in $\mathrm{WCH}$ cases, whereas they are abnormal in mild HT cases [20].

According to our experience, there are many patients not using any antihypertensive medication, which has been evaluated just after a single office BP measurement, but actually they have MHT. Prevalence of $\mathrm{WCH}$ and MHT increased with aging in a previous study [15]. Whereas we observed an increased prevalence of MHT by aging, too, but the prevalence of $\mathrm{WCH}$ increased until the fourth decade and then began to decrease, and was lowered to $8 \%$ in the eighth decade, whereas it was higher than $40 \%$ in the third, fourth, and fifth decades of life [20]. We detected prevalence of MHT as lower than 5\% until the seventh decade of life and it was 7\% in seventh and $16 \%$ in the eighth decades [20]. Its rate never exceeded $25 \%$ of all HT cases [20]. As an opposite finding to us, MHT was detected as common as $\mathrm{WCH}$, and masking was correlated with male sex and young age, thus suggesting a causal relationship with greater daytime physical activity [31]. Whereas according to our results, $\mathrm{WCH}$ is a much frequent phenomenon than MHT until the eighth decade, and MHT is mainly detected in elders [20]. Additionally, MHT showed an equal sexual distribution in our study [20]. As a parallel finding to us, the prevalence of $\mathrm{WCH}$ was found to be $5 \%$ between the ages of 65 and 70 
Page 3 of 4

years in another study [32]. But in the same study, the white coat effect was found to be more marked for systolic than diastolic BP, and the study was concluded as previously observed higher BPs seen in the elders may be explained by the greater white coat effect. Whereas, diastolic white coat effect was observed in $64 \%$, diastolic and systolic in $33 \%$, and systolic alone only in $2 \%$ of the $\mathrm{WCH}$ cases by us [20]. According to our opinion, due to the very high prevalence of $\mathrm{WCH}$ even in early decades and sexual distribution differences between $\mathrm{WCH}$ and HT cases, WCH should be thought as a response of the body against various stresses including weight gain.

Smoking alone may be one of the major underlying causes of the systemic atherosclerotic process, and even cancers [33,34]. Its atherosclerotic effect is the most obvious in Buerger's disease. It is an inflammatory disease characterized by obliterative changes in small and medium-sized arteries and veins, and it has never been documented in nonsmokers. Although the well-known strong atherosclerotic effects of smoking, some studies reported that smoking in humans and nicotine administration in animals are associated with a decrease of body weight [35]. Evidence revealed an increased energy expenditure while smoking both on rest and light physical activity [36], and nicotine supplied by patch after smoking cessation decreased caloric intake in a dose-related manner [37]. According to an animal study, nicotine may lengthen intermeal time, and decreases amount of meal eaten [38]. Additionally, body weight seems to be the highest in former, the lowest in current, and medium in never smokers [39]. Smoking may be associated with post cessation weight gain, but evidence suggests that risk of weight gain is the highest during the first year after quitting and declines over the years [40]. Similarly, although the CHD were detected with similar prevalence in both sexes in the previous study prevalence of smoking and COPD were higher in males against the higher prevalence of BMI and its terminal consequences including HT and DM in females [33]. This result may indicate both the weight decreasing and strong atherosclerotic effects of smoking. Similarly, the incidence of a myocardial infarction is increased sixfold in women and threefold in men who smoke at least 20 cigarettes per day compared to the never smoked cases [41]. Similar to the previous study the proportion of smokers is consistently higher in men in the literature $[33,34]$. So smoking is probably a powerful atherosclerotic factor with some suppressor effects on appetite. But smoking may also show the weakness of volition to control eating in the metabolic syndrome, so it may indicate additional risk of excess weight and its consequences. Similarly, prevalence of HT, DM, and smoking were the highest in the highest triglyceride having group as a significant indicator of the metabolic syndrome [8].

\section{Conclusion}

As a conclusion, metabolic syndrome is an accelerated systemic atherosclerotic process terminating with obesity, HT, DM, PAD, CRD, COPD, cirrhosis, CHD, stroke, and eventually early aging and death. It shows itself with some reversible components including smoking, overweight, hyper-betalipoproteinemia, hypertriglyceridemia, dyslipidemia, IFG, IGT, and WCH. The terminal consequences are probably due to the smoking and excess weight induced chronic inflammatory process on the endothelial system for a long period of time. WCH is a pioneer sign of the accelerated systemic atherosclerotic process that can be detected easily, and treated by preventing weight gain.

\section{References}

1. Eckel RH, Grundy SM, Zimmet PZ (2005) The metabolic syndrome. Lancet 365: 1415-1428.

2. Grundy SM, Brewer HB Jr, Cleeman JI, Smith SC Jr, Lenfant C (2004) Definition of metabolic syndrome: Report of the National Heart, Lung, and Blood Institute/American Heart Association conference on scientific issues related to definition. Circulation 109: 433-438.

3. Tonkin AM (2006) The metabolic syndrome(s)? Curr Atheroscler Rep 6: 165-166.

4. Franklin SS, Barboza MG, Pio JR, Wong ND (2006) Blood pressure categories, hypertensive subtypes, and the metabolic syndrome. J Hypertens 24: 2009-2016.

5. Helvaci MR, Kaya H, Gundogdu M (2012) Gender differences in coronary heart disease in Turkey. Pak J Med Sci 28: 40-44.

6. Helvaci MR, Kaya H, Gundogdu M (2012) White coat hypertension may be an initial sign of metabolic syndrome. Acta Med Indones 44: 222-227.

7. Helvaci MR, Kaya H, Sevinc A, Camci C (2009) Body weight and white coat hypertension. Pak J Med Sci 25: 6: 916-921.

8. Helvaci MR, Kaya H, Gundogdu M (2010) Association of increased triglyceride levels in metabolic syndrome with coronary artery disease. Pak J Med Sci 26: 667-672.

9. Calle EE, Thun MJ, Petrelli JM, Rodriguez C, Heath CW Jr (1999) Bodymass index and mortality in a prospective cohort of U.S. adults. N Engl J Med 341: 1097-1105.

10. Helvaci MR, Ozcura F, Kaya H, Yalcin A (2007) Funduscopic examination has limited benefit for management of hypertension. Int Heart J 48: 187-194.

11. Helvaci MR, Kaya H, Yalcin A, Kuvandik G (2007) Prevalence of white coat hypertension in underweight and overweight subjects. Int Heart J 48: 605-613.

12. Azadbakht L, Mirmiran P, Esmaillzadeh A, Azizi T, Azizi F (2005) Beneficial effects of a Dietary Approaches to Stop Hypertension eating plan on features of the metabolic syndrome. Diabetes Care 28: 2823-2831.

13. Volek JS, Feinman RD (2005) Carbohydrate restriction improves the features of Metabolic Syndrome. Metabolic Syndrome may be defined by the response to carbohydrate restriction. Nutr Metab (Lond) 2: 31.

14. Helvaci MR, Kaya H, Borazan A, Ozer C, Seyhanli M, et al. (2008) Metformin and parameters of physical health. Intern Med 47: 697-703.

15. (2002) Third Report of the National Cholesterol Education Program (NCEP) Expert Panel on Detection, Evaluation, and Treatment of High Blood Cholesterol in Adults (Adult Treatment Panel III) final report. Circulation 106: 3143-3421.

16. Ohkubo T, Asayama K, Kikuya M, Metoki H, Hoshi H, et al. (2004) How many times should blood pressure be measured at home for better prediction of stroke risk? Ten-year follow-up results from the Ohasama study. J Hypertens 22: 1099-1104.

17. Chobanian AV, Bakris GL, Black HR, Cushman WC, Green LA, et al. (2003) The Seventh Report of the Joint National Committee on Prevention, Detection, Evaluation, and Treatment of High Blood Pressure: the JNC 7 report. JAMA 289: 2560-2572.

18. Hond ED, Celis H, Fagard R, Keary L, Leeman M, et al. (2003) THOP investigators. Self-measured versus ambulatory blood pressure in the diagnosis of hypertension. J Hypertens 21: 717-722.

19. Stergiou GS, Salgami EV, Tzamouranis DG, Roussias LG (2005) Masked hypertension assessed by ambulatory blood pressure versus home blood pressure monitoring: is it the same phenomenon? Am J Hypertens 18: $772-778$.

20. Helvaci MR, Seyhanli M (2006) What a high prevalence of white coat hypertension in society! Intern Med 45: 671-674.

21. Polonia JJ, Gama GM, Silva JA, Amaral C, Martins LR, et al. (2005) Sequential follow-up clinic and ambulatory blood pressure evaluation in a low risk population of white-coat hypertensive patients and in normotensives. Blood Press Monit 10: 57-64. 
Citation: Helvaci RM, Ozcan A (2015) White Coat Hypertension is a Pioneer Sign of Metabolic Syndrome. J Metabolic Synd 4: 172. doi:

Page 4 of 4

22. Fagard RH, Van Den Broeke C, De Cort P (2005) Prognostic significance of blood pressure measured in the office, at home and during ambulatory monitoring in older patients in general practice. J Hum Hypertens 19: 801-807.

23. Nakashima T, Yamano S, Sasaki R, Minami S, Doi K, et al. (2004) Whitecoat hypertension contributes to the presence of carotid arteriosclerosis. Hypertens Res 27: 739-745.

24. Ugajin T, Hozawa A, Ohkubo T, Asayama K, Kikuya M, et al. (2005) White-coat hypertension as a risk factor for the development of home hypertension: the Ohasama study. Arch Intern Med 165: 1541-1546.

25. Mule G, Nardi E, Cottone S, Cusimano P, Incalcaterra F, et al. (2007) Metabolic syndrome in subjects with white-coat hypertension: impact on left ventricular structure and function. J Hum Hypertens 21: 854-860.

26. Hozawa A, Ohkubo T, Kikuya M, Yamaguchi J, Ohmori K, et al. (2002) Blood pressure control assessed by home, ambulatory and conventional blood pressure measurements in the Japanese general population: the Ohasama study. Hypertens Res 25: 57-63.

27. Celis H, Fagard RH (2004) White-coat hypertension: a clinical review. Eur J Intern Med 15: 348-357.

28. Helvaci MR, Kaya H, Duru M, Yalcin A (2008) What is the relationship between white coat hypertension and dyslipidemia? Int Heart J 49: 87-93.

29. Helvaci MR, Kaya H, Seyhanli M, Cosar E (2007) White coat hypertension is associated with a greater all-cause mortality. J Health Sci 53: $156-160$.

30. Bjorklund K, Lind L, Vessby B, Andrén B, Lithell H (2002) Different metabolic predictors of white-coat and sustained hypertension over a 20 year follow-up period: a population-based study of elderly men. Circulation 106: 63-68.

31. O'Brien E, Asmar R, Beilin L, Imai Y, Mallion JM, et al. (2003) European Society of Hypertension recommendations for conventional, ambulatory and home blood pressure measurement. J Hypertens 21: 82-848.

32. Hunt KJ, Resendez RG, Williams K, Haffner SM, Stern MP (2004) National Cholesterol Education Program versus World Health
Organization metabolic syndrome in relation to all-cause and cardiovascular mortality in the San Antonio Heart Study. Circulation 110: 1251-1257.

33. Helvaci MR, Aydin Y, Gundogdu M (2012) Smoking induced atherosclerosis in cancers. HealthMED 6: 3744-3749.

34. Fodor JG, Tzerovska R, Dorner T, Rieder A (2004) Do we diagnose and treat coronary heart disease differently in men and women? Wien Med Wochenschr 154: 423-425.

35. Grunberg NE, Greenwood MR, Collins F, Epstein LH, Hatsukami D, et al. (1992) National working conference on smoking and body weight. Task Force 1: Mechanisms relevant to the relations between cigarette smoking and body weight. Health Psychol 11: 4-9.

36. Walker JF, Collins LC, Rowell PP, Goldsmith LJ, Moffatt RJ, et al. (1999) The effect of smoking on energy expenditure and plasma catecholamine and nicotine levels during light physical activity. Nicotine Tob Res 1: 365-370.

37. Hughes JR, Hatsukami DK (1997) Effects of three doses of transdermal nicotine on post-cessation eating, hunger and weight. J Subst Abuse 9: 151-159.

38. Miyata G, Meguid MM, Varma M, Fetissov SO, Kim HJ (2001) Nicotine alters the usual reciprocity between meal size and meal number in female rat. Physiol Behav 74: 169-176.

39. Laaksonen M, Rahkonen O, Prattala R (1998) Smoking status and relative weight by educational level in Finland, 1978-1995. Prev Med 27: 431-437.

40. Froom P, Melamed S, Benbassat J (1998) Smoking cessation and weight gain. J Fam Pract 46: 460-464.

41. Prescott E, Hippe M, Schnohr P, Hein HO, Vestbo J (1998) Smoking and risk of myocardial infarction in women and men: longitudinal population study. BMJ 316: 1043-1047. 